\title{
RESEARCH IN IMPACT OF CARGO VEHICLE LOAD WEIGHT ON BRAKING SYSTEM ELEMENT HEATING PROCESS IN SINGLE EMERGENCY STOPPING
}

\author{
Andrzej Borawski \\ Bialystok University of Technology, Poland \\ a.borawski@pb.edu.pl
}

\begin{abstract}
The paper presents the results of the simulation tests of the impact of the total vehicle weight (with load) on heating discs and brake pads. It was necessary to develop a mathematical model describing the braking process of the truck to perform the simulation. The necessary material features, such as: coefficient of friction, thermal conductivity, density and thermal capacity at constant pressure were determined experimentally using laboratory equipment. Vehicle technical data were obtained from the manufacturer. The tests were carried out for constant initial speed $-90 \mathrm{~km} \cdot \mathrm{h}^{-1}$. For the purposes of this paper, a CAD model with the working elements of the braking system (disc and pad) was developed. The geometry of the system has been simplified relative to real parts. The simplification involved removal of unnecessary complicated geometry that does not have a significant impact on the final result of the tests, but may cause unnecessary compaction of the mesh. The finite element method (FEM) was used for the calculations. Appropriate equipment was also needed. In the case under consideration, a computer equipped with Comsol Multiphysics software was used. This is the software commonly used to calculate the distribution of temperature fields. As the result of calculations, this software allows to measure the temperature at any time and any point of the tested system. In this case, the temperature was measured at two points: inside the brake disc and inside the brake pad. In both cases at a distance of $0.05 \mathrm{~mm}$ from the friction surface. The results clearly show that the mass of the vehicle has a direct effect on the maximum temperature of the friction linings. With overloaded vehicles, it reaches dangerously high values. Overheating the brakes may result in the fading phenomenon and loss of the stopping ability.
\end{abstract}

Keywords: simulation study, brakes, delivery vehicles, friction, wear.

\section{Introduction}

Nowadays, road transport is very extensive. The lifestyle of many people dictates the need to transport many types of goods [1]. A significant part of the whole of this industry is transport by small vehicles, which mass does not exceed 3.5t [2]. The advantage of using this category of vehicles is the possibility of driving them by persons authorized to drive passenger vehicles, lower fuel consumption and better manoeuvrability compared to a typical truck.

Locally used delivery vehicles usually have large (in volume) cargo spaces. This fact may encourage users to fully load, which often leads to exceeding the permissible total weight of the vehicle. This procedure results from the desire to save financial resources and time (transporting a larger load at one time can generate savings on fuel costs and reduce the delivery time, as the driver can make delivery to several pickup points during one trip). However, this may have dangerous consequences. The greater mass means that the moving vehicle has a higher kinetic energy [3]. Its emergency stop will therefore be much more difficult. The braking distance will be longer and there may be a risk of overheating the friction pair [4]. This, in turn, may lead to the occurrence of the socalled fading phenomena [5]. This phenomenon occurs, when the matrix of the friction material is sublimated causing formation of a gas cushion between the friction surfaces. The value of the coefficient of friction drops almost to zero then, preventing therefore the vehicle from stopping effectively [6; 7].

In delivery vehicles, the most commonly used brake system is the friction disc brake type. The working elements in this solution are: discs rotating together with the wheel, and brake pads located in the callipers [8]. When the driver decides to turn on the brakes, the contact pressure is increased, which translates into a friction torque. Because of that brakes can be considered as a kind of energy converter (there is a change of kinetic energy into heat energy $[9 ; 10])$. The energy in this form is discharged into the atmosphere and into the immediate surroundings (brake fluid, rim, tire, suspension components, etc.), which, unfortunately, can also lead to internal thermal and mechanical stress and damage as a result in extreme cases $[11 ; 12]$.

Having the above in mind, the aim of the study was to develop a mathematical model of the delivery vehicle braking process and then check how the amount of transported load affects the heating process of the braking system working elements. 


\section{Materials and methods}

The object of the research was the CAD model of the pad and disc of a popular delivery vehicle in Poland. The CAD model was made on the basis of technical documentation gathered from the manufacturer, and then simplified (Fig. 1) (elements that do not have a significant impact on the test results (e.g. holes for pins), but could introduce unnecessary mesh density, and thus, among others, extension of the test time, were removed). It was also assumed that the nominal weight (ready to run) of the vehicle is $1975 \mathrm{~kg}$.

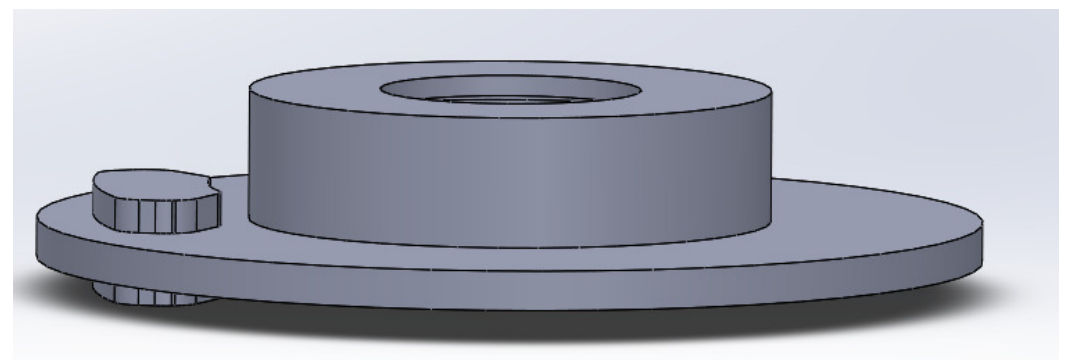

Fig. 1. CAD model of the disc and brake pads (simplified)

It was assumed that the disc material is cast iron. The data used in the study are summarized in Table 1 . The pad is a composite material. Its main components are: metal fibers $(\mathrm{Cu}$, Steel and $\mathrm{Al})$ $\approx 13 \%$, organic fibers $\approx 18 \%$, matrix (resin) $\approx 21 \%$, solid lubricants (graphite, MoS2) $\approx 8 \%$, abrasive $(\mathrm{ZrSiO} 4) \approx 15 \%$ and fillers $(\mathrm{BaSO} 4, \mathrm{Ca}(\mathrm{OH}) 2) \approx 25 \%$. The whole creates a friction material, of which the most important characteristics determined experimentally are presented in Table 2.

Table 1

Selected properties of the brake disc material

\begin{tabular}{|c|c|}
\hline Property & Value \\
\hline $\begin{array}{c}\text { Thermal } \\
\text { conductivity }\end{array}$ & $47 \mathrm{~W} \cdot(\mathrm{m} \cdot \mathrm{K})^{-1}$ \\
\hline Density & $7870 \mathrm{~kg} \cdot \mathrm{m}^{-3}$ \\
\hline $\begin{array}{c}\text { Thermal capacity at } \\
\text { constant pressure }\end{array}$ & $498 \mathrm{~J} \cdot(\mathrm{kg} \cdot \mathrm{K})^{-1}$ \\
\hline
\end{tabular}

Selected properties of the brake pad material

Table 2

\begin{tabular}{|c|c|}
\hline Property & Value \\
\hline $\begin{array}{c}\text { Thermal } \\
\text { conductivity }\end{array}$ & $146 \mathrm{~W} \cdot(\mathrm{m} \cdot \mathrm{K})^{-1}$ \\
\hline Density & $2845 \mathrm{~kg} \cdot \mathrm{m}^{-3}$ \\
\hline $\begin{array}{c}\text { Thermal capacity at } \\
\text { constant pressure }\end{array}$ & $1034 \mathrm{~J} \cdot(\mathrm{kg} \cdot \mathrm{K})^{-1}$ \\
\hline
\end{tabular}

There are many available research methods [13]. In this work it was decided to perform simulation tests. The reason for the decision was the numerous of benefits, e.g. low cost of research and short time of obtaining results $[14,15]$. Unfortunately, this method also has its drawbacks. It is necessary to develop a mathematical model that accurately reflects the actual physical phenomenon; otherwise the results may be subject to an error affecting the final results [16-18].

The COMSOL Multiphysics software was used in this study. It is software, which is using FEM (fine element method). The mesh imposed on the developed model consisted of about 7000 elements, mostly triangular shaped, which gave nearly 38000 DOFs (degrees of freedom).

It was decided that simulation tests will be performed for the emergency braking process from the initial speeds of $90 \mathrm{~km} \cdot \mathrm{h}^{-1}$ and $120 \mathrm{~km} \cdot \mathrm{h}^{-1}$ (maximum allowed speed on interstate and highway). The braking result in any case is complete stop of the vehicle. It was also assumed that the coefficient of friction of the tire to the road is 1.0 , which as a result gives a constant braking delay of $9.81 \mathrm{~m} \cdot \mathrm{s}^{-2}$. For tires size $225 / 65 \mathrm{R} 16 \mathrm{C}$, the wheel dynamic radius equals $301 \mathrm{~mm}$. The lab experiment (on pin-on-disc 
test stand) allowed to determine the coefficient of friction between the pad and the disc. The research has shown that its value is 0.44 . The determined value was used for simulation. Also, the ambient temperature of air was set on $20^{\circ} \mathrm{C}$. The tests were carried out for different loading levels. The total weight of the vehicle was assumed: $3000 \mathrm{~kg}, 3500 \mathrm{~kg}$ and $4000 \mathrm{~kg}$ (for a partially loaded vehicle, at full load and overload). The following assumptions were also made: constant coefficients of friction, contact pressure for both pads is stable and homogeneous, the brake pad material is homogeneous and its contact with the disc is by full surface, constant braking deceleration and no external factors causing deceleration (such as road inconsistencies, air resistance).

The negative derivative of the vehicle kinetic energy can describe the brakes' retardation power [19]:

$$
P=-\frac{d}{d t} \cdot\left(\frac{m v^{2}}{2}\right) ; 0 \leq t \leq t_{s}
$$

or

$$
P=-m R^{2} \omega(t) \alpha ; 0 \leq t \leq t_{s}
$$

where $m$ - vehicle mass, $\mathrm{kg}$;

$v$ - speed of the vehicle, $\mathrm{m} \cdot \mathrm{s}^{-1}$;

$R$ - dynamic radius of the road wheel, $\mathrm{m}$;

$\omega-$ angular velocity of the wheel, RPM

$t$ - time, s;

$t_{s}$ - braking time, s;

$\alpha$ - angular deceleration, $\mathrm{rad} \cdot \mathrm{s}^{-2}$.

When the braking deceleration is constant:

$$
\omega(t)=\omega_{o}+\alpha t ; 0 \leq t \leq t_{s}
$$

The vehicle stability analysis demonstrated that approximately $60 \%$ of the total braking force comes from the front wheels (on the front axis roughly $15 \%$ per each of the four brake pads). Therefore, the assumption was made that there is identical braking force on each of the brake pads. The relation between the complete vehicle braking force and the braking force of one wheel is as follows:

$$
F_{b}=\frac{100 \% \cdot F_{f b}}{2 \cdot 15 \%} \approx 3.33 F_{f b}
$$

where $F_{f b}$ - braking force generated by one front wheel, $\mathrm{N}$;

$F_{b}$ - total braking force of the vehicle, N.

Heaving the above in mind, the retardation power can be described as:

$$
P=-3.33 \iint f_{f} \cdot d A \cdot v_{d}
$$

where $f_{f}$ - frictional force per surface unit;

$v_{d}=\omega(t) \cdot r-$ brake disc linear speed at radius $r, \mathrm{~m} \cdot \mathrm{s}^{-1}$;

$A-$ disc and pad contact surface area, $\mathrm{m}^{2}$.

The braking retardation power could be also expressed by the equation [20]:

$$
P=f_{f}(t) \cdot \omega(t) \iint r_{m} \cdot d A ; 0 \leq t \leq t_{s}
$$

where $r_{m}$-distance from the pad centre of mass to the disc rotation axis, $\mathrm{m}$.

When we compare these two equations, it is possible to determine the $f_{f}$ coefficient:

$$
f_{f}=-\frac{m R^{2} \alpha}{3.33 r_{m} A}
$$

Assuming that the vehicle's deceleration occurs only through the action of the brake disc and pad, the heat flux can be expressed using the equation [21]:

$$
q(r, t)=-f_{f} \cdot v_{d}(r, t) ; 0 \leq t \leq t_{s} ; r_{0} \leq r \leq r_{m}
$$


or

$$
q(r, t)=-\frac{m R^{2} \alpha}{3.33 r_{m} A} r\left(\omega_{o}+\alpha t\right) ; 0 \leq t \leq t_{s} ; r_{0} \leq r \leq r_{m}
$$

The contact pressure is possible to be determined from the Amonton-Coulomb friction law $[22 ; 23]$, which in the analysed case is as follows:

$$
p=\frac{P}{\mu \cdot v}
$$

where $\mu$-coefficient of friction between the disc and pad;

$F_{b}$ - total braking force of the vehicle, $\mathrm{N}$.

The study takes also in account the heat exchange between the disc and pad. It can be expressed by modifying the equation from [24]:

$$
\begin{gathered}
\rho \cdot C_{p} \frac{\partial T}{\partial t}+\nabla \cdot(-k \cdot \nabla T)=Q-\rho \cdot C_{p} \cdot u \cdot \nabla T \\
T\left(r, \beta, 0^{+}, t\right)=T\left(r, \beta, 0^{-}, t\right) ; \quad(r, \beta) \in A
\end{gathered}
$$

where $k$-thermal conductivity, $\mathrm{W} \cdot(\mathrm{m} \cdot \mathrm{K})^{-1}$;

$C_{p}$ - thermal capacity, $\mathrm{J} \cdot(\mathrm{kg} \cdot \mathrm{K})^{-1}$;

$u$ - heat flux rate, $\mathrm{W} \cdot \mathrm{m}^{-2}$;

$Q$ - heating power per density unit;

$\rho$-density, $\mathrm{kg} \cdot \mathrm{m}^{-3}$;

$T$ - temperature, ${ }^{\circ} \mathrm{K}$;

$\beta$ - circumferential coordinate, $\mathrm{rad}$. released:

During the action of the brakes (through convection and radiation) the following amount of heat is

$$
q_{d}=-h\left(T-T_{r}\right)-\varepsilon \sigma\left(T^{4}-T_{r}^{4}\right)
$$

where $\left(T-T_{r}\right)$ - temperature difference between the friction material and ambient temperature, $\mathrm{K}$; $h$ - convection coefficient, $\mathrm{W} \cdot\left(\mathrm{m}^{2} \cdot \mathrm{K}\right)^{-1}$;

$\varepsilon$ - emissivity of the material;

$\sigma-$ Stefan-Boltzman constant. follows:

The relation between the speed of the vehicle and the convection coefficient can be described as

$$
h=\frac{0.037 k}{l}\left(\frac{\rho \cdot l \cdot v}{\mu_{v}}\right)^{0.8} \cdot\left(\frac{C_{p} \cdot \mu_{v}}{k}\right)^{0.33}
$$

where $\mu_{v}$ - viscosity, $\mathrm{Pa} \cdot \mathrm{s}$;

$l$ - disc diameter, $\mathrm{m}$.

\section{Results and discussion}

The direct result of the simulation tests is temperature data of the tested elements. The measuring points were set $0.1 \mathrm{~mm}$ below the contact surface in the geometrical center of the cooperation surface. The temperature profiles of the brake disc and pad are shown in Fig. 2 and Fig. 3. In addition, the amount of energy generated in the braking process was estimated for each case (Tab. 3).

The obtained data were compared with the results of similar works by other researchers [25-27]. Although the results were presented in a slightly different form, the values are proportional. This allowed to assess the correctness of the research.

The obtained results show how high temperatures are achieved in the braking system during emergency braking. The highest temperature reached by the brake pads (just over $734^{\circ} \mathrm{K}$ ) was when overloaded vehicle (weighing $4 \mathrm{t}$ ) was stopping from an initial speed of $120 \mathrm{~km} \cdot \mathrm{h}^{-1}$. The maximum was reached only $1.95 \mathrm{~s}$ from the start of braking. Brake discs in the same operating conditions 
reached a slightly lower temperature $-689^{\circ} \mathrm{K}$. It occurred $0.05 \mathrm{~s}$ earlier, $1.9 \mathrm{~s}$ from the beginning of braking. The characteristic collapse on the brake pad temperature charts results from the contact of materials with different properties (heat conduction from one element to the other).

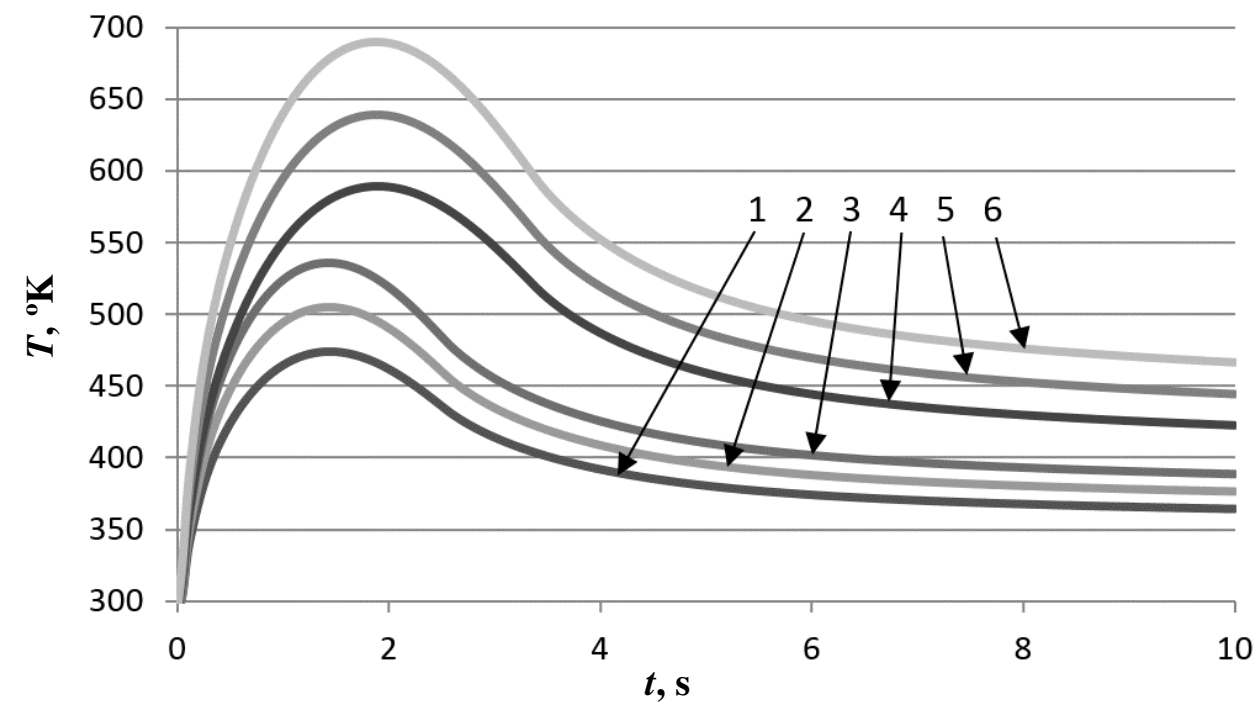

Fig. 2. Temperature profile of brake disc: 1 - initial speed $90 \mathrm{~km} \cdot \mathrm{h}^{-1}$, total mass $3000 \mathrm{~kg} ; 2$ - initial speed $90 \mathrm{~km} \cdot \mathrm{h}^{-1}$, total mass $3500 \mathrm{~kg} ; 3$ - initial speed $90 \mathrm{~km} \cdot \mathrm{h}^{-1}$, total mass $4000 \mathrm{~kg}$; 4 - initial speed $120 \mathrm{~km} \cdot \mathrm{h}^{-1}$, total mass $3000 \mathrm{~kg} ; 5$ - initial speed $120 \mathrm{~km} \cdot \mathrm{h}^{-1}$, total mass $3500 \mathrm{~kg} ; 6$ - initial speed $120 \mathrm{~km} \cdot \mathrm{h}^{-1}$, total mass $4000 \mathrm{~kg}$

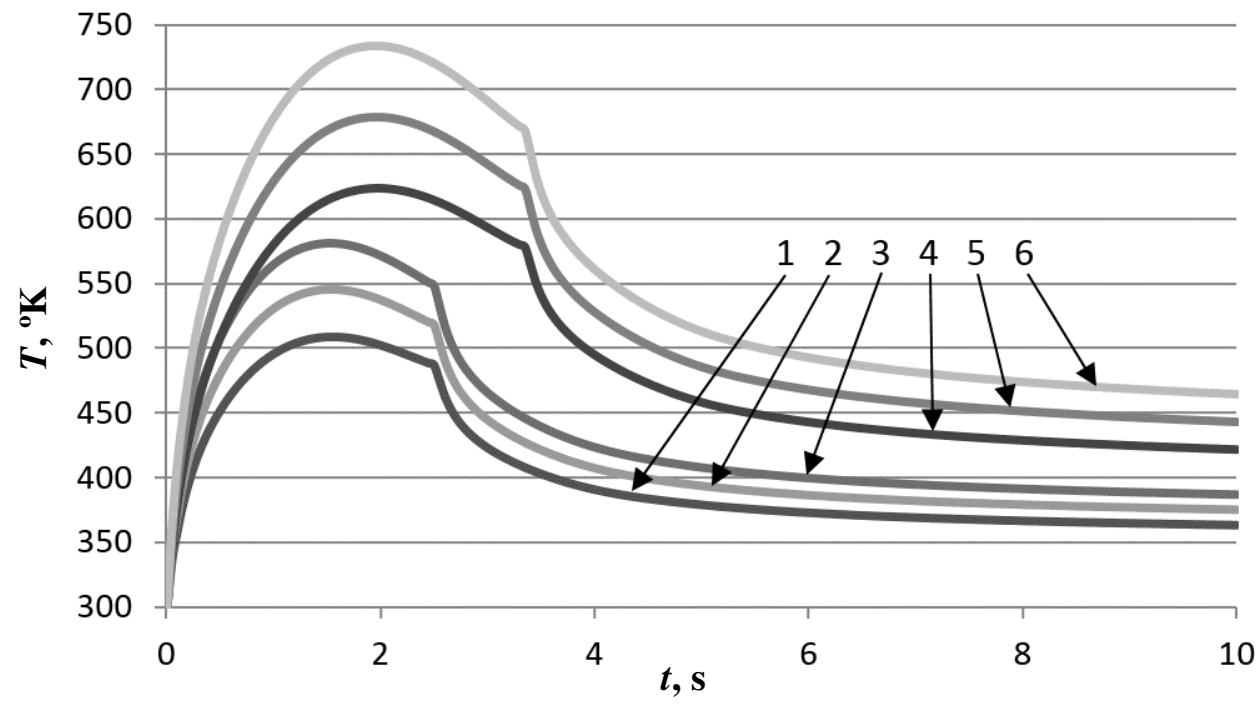

Fig. 3. Temperature profile of brake pad: 1 - initial speed $90 \mathrm{~km} \cdot \mathrm{h}^{-1}$, total mass $3000 \mathrm{~kg} ; 2$ - initial speed $90 \mathrm{~km} \cdot \mathrm{h}^{-1}$, total mass $3500 \mathrm{~kg} ; 3$ - initial speed $90 \mathrm{~km} \cdot \mathrm{h}^{-1}$, total mass $4000 \mathrm{~kg}$; 4 - initial speed

$120 \mathrm{~km} \cdot \mathrm{h}^{-1}$, total mass $3000 \mathrm{~kg} ; 5$ - initial speed $120 \mathrm{~km} \cdot \mathrm{h}^{-1}$, total mass $3500 \mathrm{~kg} ; 6$ - initial speed

$120 \mathrm{~km} \cdot \mathrm{h}^{-1}$, total mass $4000 \mathrm{~kg}$

Table 3

Amount of energy generated in the braking process

\begin{tabular}{|c|c|c|}
\hline Initial speed, $\mathbf{~ k m} \cdot \mathbf{h}^{-1}$ & Total mass, $\mathbf{~ g g}$ & Generated energy, W \\
\hline \multirow{3}{*}{90} & 3000 & 144155 \\
\cline { 2 - 3 } & 3500 & 168196 \\
\cline { 2 - 3 } & 4000 & 192233 \\
\hline \multirow{3}{*}{120} & 3000 & 256310 \\
\cline { 2 - 3 } & 3500 & 299038 \\
\cline { 2 - 3 } & 4000 & 341766 \\
\hline
\end{tabular}


It should be remembered that the brake pads are made of a composite material, which resin is the matrix. It is a material that has limited resistance to heat load. Depending on the type of resin, damage to its structure may occur when heated to $400-500{ }^{\circ} \mathrm{C}[28 ; 29]$. The weakest of them burn already at $260^{\circ} \mathrm{C}\left(533^{\circ} \mathrm{K}\right)[30]$. Therefore, attempts are being made to develop some modifications to improve resistance to high temperatures [31]. However, in the case of conventional solutions, intensive heating of rubbing couple causes the occurrence of the fade phenomenon. In the present case, it turns out that $2 / 3$ of the stopping processes under investigation are threatened by the appearance of a gas cushion in the friction couple. Safe driving conditions can be considered traveling with a fully loaded vehicle at a speed of $90 \mathrm{~km} \cdot \mathrm{h}^{-1}$. Increasing the speed or load carries the risk of overheating the brakes.

\section{Conclusions}

1. A mathematical model of the delivery vehicle braking process was developed in the paper.

2. Performed simulation tests based on the developed model allowed to measure the temperature of the braking system components at any time and at any point.

3. The highest temperatures were achieved when braking from $120 \mathrm{~km} \cdot \mathrm{h}^{-1}$ with a total weight of $4000 \mathrm{~kg}$.

4. Overloading the vehicle or moving at excessive speeds carries the risk of overheating the brakes, which can lead to fade.

\section{Funding}

This publication was financed through the program of the Ministry of Science and Higher Education of Poland named "Regional Initiative of Excellence" in 2019-2022 project number 011/RID/2018/19.

\section{Acknowledgments}

This research was co-founded through the subsidy of the Ministry of Science and Higher Education for the discipline of Mechanical Engineering at the Faculty of Mechanical Engineering, Bialystok University of Technology.

\section{References}

[1] Szpica D. New Leiderman-Khlystov Coefcients for Estimating Engine Full Load Characteristics and Performance. Chinese Journal of Mechanical Engineering, vol. 32, 2019, pp. 1-14

[2] Vissera J., Nemoto T., Browne M. Home Delivery and the Impacts on Urban Freight Transport: A Review. Procedia - Social and Behavioral Sciences, vol. 125, 2014, pp. 15-27.

[3] Borawski A. Simulation Study of the Process of Friction in the Working Elements of a Car Braking System at Different Degrees of Wear. Acta Mechanica et Automatica, vol. 12(3), 2018, pp. 221-226.

[4] Adamowicz A. Thermal stress state of the pad-disc tribosystem ad single braking. Journal of Friction and Wear, vol. 38(2), 2017, pp. 24-30.

[5] Towoju O.A. Braking Pattern Impact on Brake Fade in an Automobile Brake System. Journal of engineering sciences, vol. 6(2), 2019, pp. 11-16.

[6] Jewtuszenko O., Kuciej M., Topczewska K. Some theoretical model for determining the temperature field of a multi-disk brake. Advances in Mechanical Engineering, vol. 12(1), 2020, pp. 1-15.

[7] Kuciej M., Topczewska K. Determination of the Maximum Temperature of the Friction Pad in a One-Disk Clutch. Materials Science, vol. 54(6), 2019, pp. 819-826.

[8] Jewtuszenko O., Kuciej M., Och E. Influence of thermal sensitivity of the pad and disk materials on the temperature during braking. International Communications in Heat and Mass Transfer, vol. 55, 2014, pp. 84-92.

[9] Kamiński Z., Kulikowski K. Measurement and evaluation of the quality of static characteristics of brake valves for ag-ricultural trailers. Measurement, vol. 106, 2017, pp. 173-178.

[10] Mieczkowski G. Description of stress fields and displacements at the tip of a rigid, flat inclusion located at interface using modified stress intensity factors. Mechanika, vol. 21(2), 2015, pp.91-98. 
[11] Kulikowski K., Szpica D. Determination of directional stiffnesses of vehicels'tires under a static load operation, Maintenance and Reliability, Vol. 16(1), 2014, pp. 66-72.

[12] Mieczkowski G. Stress fields at the tip of a sharp inclusion on the interface of a bimaterial. Mechanics of Composite Materials, vol. 52(5), 2016, pp.601-610.

[13] Borawski A. Common methods in analysing the tribological properties of brake pads and discs - a review. Acta Mechanica et Automatica, vol. 13(3), 2019, pp. 189-199.

[14] Mieczkowski G., Borawski A., Szpica D. Static electromechanical characteristic of a three-layer circular piezoelectric transducer. Sensors, vol. 20, 2020, 222, pp. 1-14.

[15] Borawski A. Suggested Research Method for Testing Selected Tribological Properties of Friction Components in Vehicle Braking Systems. Acta Mechanica et Automatica, vol. 10(3), 2016, pp. 223-226.

[16] Szpica D. The influence of selected adjustment parameters on the operation of LPG vapor phase pulse injectors, Journal of Natural Gas Science and Engineering, vol. 34, 2016, pp. 1127-1136.

[17] Szpica D. Investigating fuel dosage non-repeatability of low-pressure gas-phase injectors. Flow Measurement and Instrumentation, vol. 59, 2018, pp. 47-156.

[18] Mieczkowski G. Optimization and Prediction of Durability and Utility Features of Three-Layer Piezoelectric Transducers. Mechanika vol. 24(3), 2018, pp.335-342.

[19] Yevtushenko O., Grzes P. 3D FE model of frictional heating and wear with a mutual influence of the sliding velocity and temperature in a disc brake. International Communications in Heat and Mass Transfer, vol. 62, 2015, pp.37-44.

[20] Richardson J.M., Coulson J.F. Chemical Engineering Vol. 1: Fluid Flow, Heat Transfer and Mass Transfer, Bath: The Bath Press, 1999, 908p.

[21] Talati, F., Jalalifar, S. Analysis of heat conduction in a disk brake system. Heat Mass Transfer, vol. 45, 2009, pp. 1047-1059.

[22] Popova E., Popov V.L. The research works of Coulomb and Amontons and generalized laws of friction. Friction. vol. 3(2), 2015, pp. 183-190.

[23] Barber J.R. Multiscale Surfaces and Amontons' Law of Friction. Tribology Letters, vol. 49, 2013, pp. 539-543.

[24] Carey V.P., Chen G., Grigoropoulos C. A Review of Heat Transfer Physics. Nanoscale and Microscale Thermophysical Engineering, vol. 12(1), 2008, pp 1-60.

[25] Yan M., Xu J. Prediction Model for Brake-Drum Temperature of Large Trucks on Consecutive Mountain Downgrade Routes Based on Energy Conservation Law. Mathematical Problems in Engineering, vol. 11, 2018, pp. 1-10.

[26] Kalkakos D., Westerhof B. Heavy Vehicle Braking using Friction Estimation for Controller Optimization, Stockholm: KTH Royal Institute of Technology, 2017, 104p.

[27]Zeng S., Zhang H., Meng Y. Research on Heat Conduction Inverse Problem of Continuous Long Downhill Truck Brake, Proceedings of "International Conference on Civil, Transportation and Environment (ICCTE 2016)", January 30-31, 2016, Guangzhou, China, pp. 407-416.

[28] Komori T., Miyake S., Senoo Y. Brake friction material (US Pat. 4954536). USA: United States Patent and Trademark Office, 1990, 5p.

[29] Kakegawa H., Yasuda T., Wang X. Binder Composition for Friction Materials, and Friction Materials (US Pat. 5889081). USA: United States Patent and Trademark Office, 1999, 10p.

[30] Avallone E.A., Baumeister T., Sadegh A.M. Marks Handbook for Mechanical Engineers, 11th edition. New York: McGraw-Hill, 2007, 1774p.

[31]Bijwe N.J. NBR-modified resin in fade and recovery module in nonasbestos organic (NAO) friction materials. Tribology Letters, vol. 27, 2007, pp. 189-196. 